\title{
Facile synthesis and characterization of mesoporous titanium oxide nanoparticles for ethanol sensing properties
}

\author{
Altaf Hussain Shar ${ }^{1}$, Muhammad Nazim Lakhan ${ }^{1}$, Jingyuan Liu ${ }^{1}$, Mukhtiar Ahmed ${ }^{1}$, \\ Muhammad Basit Chandio ${ }^{2}$, Ahmer Hussain Shah ${ }^{3}$, Abdul Hanan ${ }^{1}$, Irfan Ali ${ }^{4}$, Jun \\ Wang ${ }^{1}$
}

\begin{abstract}
:
Mesoporous $\mathrm{TiO}_{2}$ nanoparticles were successfully synthesized via solvothermal. The morphology and crystal structure was characterized by UV-vis spectrum (UV-Vis), Fourier Transform Infrared (FTIR) spectroscopy, X-ray diffraction (XRD), Scanning electron microscopy (SEM) and transmission electron microscopy (TEM). All the observations confirmed that the as-fabricated mesoporous $\mathrm{TiO}_{2}$ nanoparticles were successfully synthesized with surface Plasmon resonance peak between a range of 250-350 $\mathrm{nm}$ and its pattern meets with the JCPDS Standard (card No. 21-1272). TEM confirmed the mesoporous structure morphology and shows the incredible gas sensing performance due to their large accessible surface area. Furthermore, the as-prepared $\mathrm{TiO}_{2}$ nanoparticles exhibited more rapid response/recovery and higher sensitivity towards ethanol at $180^{\circ} \mathrm{C}$ distinguished with isopropyl alcohol and methanol. In addition, it can be affirmed that the synthesized mesoporous $\mathrm{TiO}_{2}$ nanoparticles are a promising applicant for fabricating high-performance ethanol gas sensor in real-time monitoring.
\end{abstract}

Keywords: Gas sensor; mesoporous; nanotechnology; $\mathrm{TiO}_{2}$; ethanol sensing.

\section{Introduction}

Currently, atmospheric environmental protection is considered as a concerning issue because of the emission of harmful gas molecules and due to the rapid development in modern industries. To mitigate this, the detection of toxic gases is extremely essential for the excellence of the environment and human health [1]. Vapor sensors based on ethanol are widely usable sensors owing to their unique properties in chemical and biomedical industries and also for the analysis of breath [2]. High sensitivity, minimum

${ }^{1}$ Key Laboratory of Superlight Material and Surface Technology, Ministry of Education, Harbin Engineering University, PR People's Republic of China.

${ }^{2}$ College of Mechanical and Electrical Engineering, Harbin Engineering University, People's Republic of China

${ }^{3}$ Department of Textile Engineering, Balochistan University of Information Technology, Engineering and Management Sciences, Quetta, Pakistan

${ }^{4}$ College of Chemical Engineering, Beijing University of Chemical Technology, People's Republic of China

Corresponding Author: altafshar12@gmail.com

$$
\text { SJET | ISSN: 2616-7069 | Vol. } 3 \text { | No. } 1 \text { | @ } 2020 \text { Sukkur IBA University }
$$


operating temperature, and less recovery time with short responses are ideal features in ethanol vapor (EV) sensors. Therefore, EV sensors and their functional materials research attracted huge attention by scientists for the development of high-performance EV sensors.

Nowadays, many sensing mechanisms and technologies have been employed for volatile organic compounds (VOCs) detection including thermal conductivity, catalyst, electrochemical, chemi-resistors types, mechanical and optical [3]. Among them, chemi-resistors based sensors are mostly preferable and economical devices with the existence of transuding platforms and acceptor materials and are broadly accepted because of their high potential application and long-term stability [4].

The gas sensing material is considered an important parameter for the selection of gas sensors. Among many, metal oxide semiconductors (MOSs) nanomaterials have attained some significant attention and considered promising material due to advantages such as; easy fabrication, fast response and recovery time, low operating cost, minimum power consumption, and minimum size with excellent chemical stability [5]. Mesoporous semiconducting metal oxides have been extensively used as the chemi-resistive based gas sensors due to their outstanding properties such as high surface area, large pores volume, high interconnection, long-term stability, high electron conductivity and enhanced sensing performance [6]. Among other metal oxides, Titanium dioxide $\left(\mathrm{TiO}_{2}\right)$ with wide-bandgap (3.4 eV) MOSs are considered as promising material Because of its distinctive properties includes chemical stability, excellent sensor performance, low cost, high activity, nontoxicity and abundance [7], and is used in various applications including batteries [8], photocatalysis, water splitting, solar cells, gas sensors, and biological application [9]. $\mathrm{TiO}_{2}$ attracts much attention in the field of gas sensors [10]. In comparison with some common MOSs gas sensors operated on high temperatures, $\mathrm{TiO}_{2}$ is favorable owing to higher sensitivity, fast response, long-term stability, and easily detectable gas at low temperatures. Various structures of $\mathrm{TiO}_{2}$ used for ethanol detection have been reported, such as nanoparticles and nanoflowers [11, 12]. However, pristine $\mathrm{TiO}_{2}$ is not widely investigated due to they are some drawbacks including low sensitivity, slow responserecovery time and limited specific area [13]. To solve these problems, many researchers committed to enhance the performance of $\mathrm{TiO}_{2}$ based sensors to modify morphology of $\mathrm{TiO}_{2}$ surface and nanostructure, as they are key factors that influence gas sensing performance [14]. Particularly, mesoporous $\mathrm{TiO}_{2}$ nanostructures have a large specific surface area which provides numerous active sites facilitating more oxygen to be adsorbed at the surface and it also allows gas molecules to easily penetrate and adsorb on the surface of sensing materials for the improvement of response recovery time and detection limit [15]. Much research has still to be made for the development of mesoporous sensing materials having properties such as high sensitivity, minimum operating temperature, short response with less recovery time, easy fabrication and environmental flexibility.

Herein, a novel ethanol vapor based sensor on mesoporous $\mathrm{TiO}_{2}$ nanoparticles has been successfully synthesized via solvothermal methods. The as-fabricated mesoporous $\mathrm{TiO}_{2}$ material microstructure properties were characterized by FTIR, UV-Vis, XRD, SEM and TEM. Furthermore, Gas sensing properties such as operating temperature, response to concentration, selectivity, response and recovery time were evaluated. 


\section{Materials and method}

\subsection{Synthesis mesoporous $\mathrm{TiO} 2$ nanoparticles:}

All the chemicals we used in this experiment are of analytical grade and used directly without any further purification prior to usage. Mesoporous $\mathrm{TiO}_{2}$ nanoparticles are prepared by an environmentally friendly and one-step Solvothermal route. In a typical process, first $20 \mathrm{ml}$ of deionized water (DW) and $40 \mathrm{ml}$ isopropyl alcohol were mixed together using magnetic stirrer until a homogeneous solution formed. Then, $6.0 \mathrm{~g}$ of titanium sulfate $\left(\mathrm{Ti}\left(\mathrm{SO}_{4}\right) 2\right)$ was added under strong stirring till a uniform solution achieved. Afterward, the aqueous solution was transferred into $100 \mathrm{ml}$ Teflon-lined stainless steel autoclave and heated at $90^{\circ} \mathrm{C}$ for $12 \mathrm{~h}$. Later, as-prepared $\mathrm{TiO}_{2}$ were centrifuged, rinsed and overnight dried at $90^{\circ} \mathrm{C}$. Finally, the dried powder was calcined in tube furnace at $300^{\circ} \mathrm{C}$ for $2 \mathrm{~h}$ in atmospheric air at a rate of $5^{\circ} \mathrm{C} / \mathrm{min}$.

\subsection{Characterization}

UV-Vis absorption spectra were calculated by using a TU-1901 dual-beam UV-Vis spectrophotometer. The FTIR spectrum of mesoporous nanoparticles was collected on $\mathrm{KBr}$ plates cast using a Perkin Elmer Spectrum 100 FTIR spectrometer. The crystal structure was investigated by XRD system with $\mathrm{Cu} \mathrm{K} 1$ radiation $(=0.15406 \mathrm{~nm})$. The surface morphology of catalyst was observed with SEM (JOEL JSM - 6480A) operated at a $20 \mathrm{kv}$ of driving voltage while TEM images were acquired by using an FEI TECNNI G2 instrument. The gas sensing measurements were tested by a commercial NMDOG multi-functional accuracy sensor analysis tester (manufactured in Changsha city, China) at room temperature.

\subsection{Fabrication and measurement of the sensor}

In a typical process, the as-prepared sensing material was fully grinded by adding a small amount of ethanol to form slurry, and then pasted it onto the ceramic tube and then heated at $60^{\circ} \mathrm{C}$ for $2 \mathrm{~h}$ to evaporate the ethanol and kept in air for one day to improve the stability of the sensing materials layer. The operating temperature was controlled by providing the heating current through the $\mathrm{Ni}$ $\mathrm{Cr}$, resistor heating wire inserted into the ceramic tube. Sensing properties of the gas sensor were measured by a commercial NMDOG Multifunctional Precision Sensor Analysis Instrument (Changsha Dingchen Scientific Instrument Co, Ltd, Hunan, China). For measurement, the saturated target vapor in corresponding amounts was injected into a closed $10 \mathrm{~L}$ chamber by a micro-syringe to obtain the different concentrations of analytes. After fully mixed with atmospheric air, the sensor was put into the chamber to measure its performance. When the response on the display reached constant value, the sensor was taken out to atmospheric air. The response of the sensor is defined as the $\mathrm{S}=\mathrm{Rg} / \mathrm{Ra}$, where $\mathrm{Rg}$ is the resistance of the sensor in target gas and $\mathrm{Ra}$ is the resistance of the sensor in air.

The response/ recovery time is defined as time spent by the sensor to achieve $90 \%$ of the total resistance change.

\section{Results and Discussion}

\subsection{UV-Visible spectrum}

The UV-Vis absorption spectrum of mesoporous $\mathrm{TiO}_{2}$ nanoparticles is shown in Fig. 1. UV-Vis spectrum of $\mathrm{TiO}_{2}$ sharp edge 250-350 nm showing mesoporous $\mathrm{TiO}_{2}$ nanoparticles absorbs light from the ultraviolet region at room temperature displaying a good absorption band in the UV region [16]. 


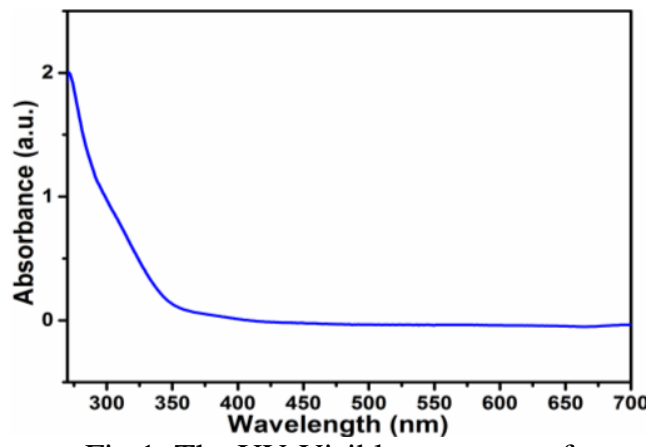

Fig 1. The UV-Visible spectrum of mesoporous titanium dioxide nanoparticles.

\subsection{FTIR analysis}

FTIR spectroscopy was used to characterize the proper surface functional groups responsible for the synthesis of mesoporous $\mathrm{TiO}_{2}$ nanoparticles as shown in Fig. 2. The intensive absorption peaks were characterized by a number of characteristic bands occurring at $3744 \mathrm{~cm}^{-1}, 3648 \mathrm{~cm}^{-1}, 2917$ $\mathrm{cm}^{-1}, 2853 \mathrm{~cm}^{-1}, 1741 \mathrm{~cm}^{-1}, 1585 \mathrm{~cm}^{-1}, 1376$ $\mathrm{cm}^{-1}$ and $1118 \mathrm{~cm}^{-1}$. The characteristic peaks were noticed between $3700 \mathrm{~cm}^{-1}$ and $3500 \mathrm{~cm}^{-}$ ${ }^{1}$ were related to $\mathrm{TiO}_{2}$ product as well as small intensity peak at $1650 \mathrm{~cm}^{-1}$ was showing stretching and bending vibrations of hydroxyl groups on the surface of $\mathrm{TiO}_{2}$ nanoparticles. Additionally, another absorption peaks situated at 2917 and $2853 \mathrm{~cm}^{-1}$ were assigned to the asymmetric and symmetric stretch vibrations of $\mathrm{CH}_{2}$ groups, $1740 \mathrm{~cm}^{-1}$ represents the stretching of $\mathrm{C}=\mathrm{O}$ aldehydes group, $1586 \mathrm{~cm}^{-1}(\mathrm{C}-\mathrm{C})$ stretches in the aromatic ring, $1420 \mathrm{~cm}^{-1}(\mathrm{CH}$ groups) and $1118 \mathrm{~cm}^{-1}(\mathrm{C}=\mathrm{O}$ stretching vibrations). The obtained peaks in spectra confirm the formation of final $\mathrm{TiO}_{2}$ products [17].

\subsection{XRD analysis}

XRD pattern confirms the composition and crystal structure of as-synthesized $\mathrm{TiO}_{2}$ nanoparticles. Materials were characterized in a range of 10-90. Fig. 3 depicted the XRD patterns of the obtained anatase $\mathrm{TiO}_{2}$ sample. All the diffraction peaks located at $2 \theta=25.2$, 37.8, 48.0, 53.9, 55.0, 62.7, 68.7, 70.3 and 75.0 could be indexed to (101), (004), (200),
(105), (211), (204), (116), (220) and (215) planes of anataseTiO2, respectively. The peaks of the anatase $\mathrm{TiO}_{2}$ phase are of (JCPDS card No. 21-1272) standard. No characteristic peaks of impurity phases were observed in the XRD pattern and sharp diffraction peaks indicated good crystallinity. The grain size of mesoporous $\mathrm{TiO}_{2}$ nanoparticles was calculated using the Scherrer formula [18].

$$
\mathrm{D}=(\mathrm{k} \lambda /(\beta \cos \theta)
$$

Where $\mathrm{D}$ is average crystallite size, $\lambda$ is the wavelength of $\mathrm{Cu} \mathrm{K} \alpha(0.154 \mathrm{~nm}), \mathrm{k}$ is a shape factor which is $0.9, \beta$ is measured from the full width at half maximum (FWHM) in radian and $\theta$ is Bragg angle it is obtained by dividing 2 the $2 \theta$ value of corresponding diffraction peak. The mean crystallite sizes of mesoporous $\mathrm{TiO}_{2}$ nanoparticles were found in the ranges of 17-24 $\mathrm{nm}$ as shown in table 1 .

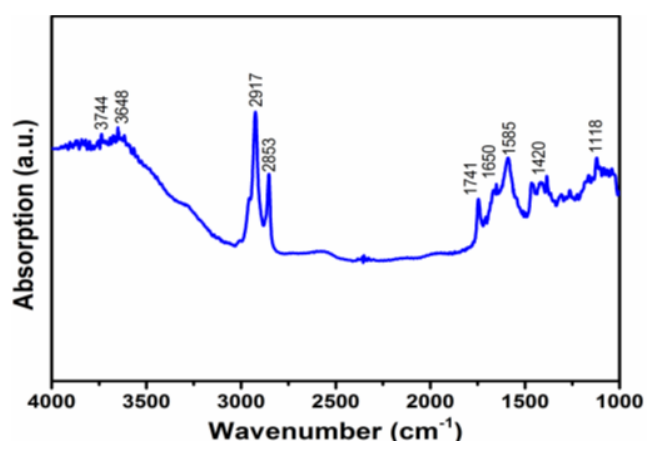

Fig 2. FTIR analysis of mesoporous $\mathrm{TiO}_{2}$ nanoparticles.

Table 1. Particle size calculation from the XRD pattern.

\begin{tabular}{|l|l|l|l|}
\hline $\begin{array}{l}\text { Lattice } \\
\text { plane }\end{array}$ & $\begin{array}{l}\text { Peak } \\
\text { Position } \\
\text { (degree) }\end{array}$ & $\begin{array}{l}\text { FWHM } \\
(\text { degree })\end{array}$ & $\begin{array}{l}\text { Particle } \\
\text { size } \\
(\mathbf{n m})\end{array}$ \\
\hline$(101)$ & 25.2 & 0.47 & 17.3 \\
\hline$(004)$ & 37.8 & 0.57 & 17.8 \\
\hline$(200)$ & 48.0 & 0.40 & 18.4 \\
\hline$(211)$ & 55.0 & 0.37 & 19.0 \\
\hline$(215)$ & 75.0 & 0.20 & 48.5 \\
\hline
\end{tabular}




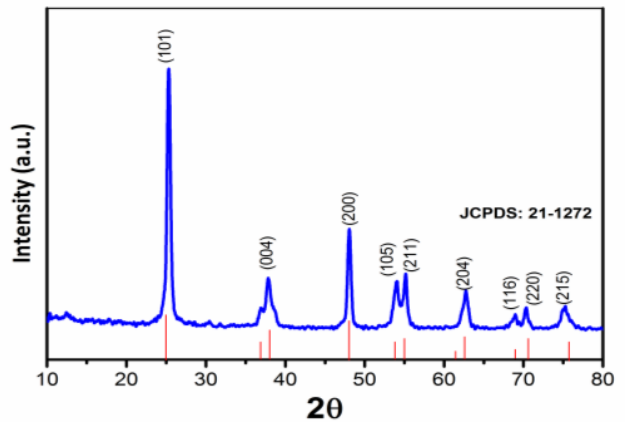

Fig 3. XRD patterns of mesoporous $\mathrm{TiO}_{2}$ nanoparticles

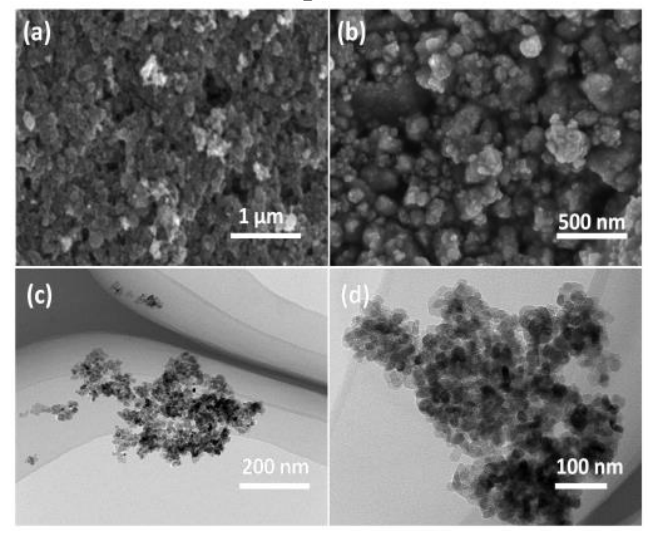

Fig 4. (a-b) SEM images of mesoporous TiO2 nanoparticles and TEM (c-d).

\subsection{Morphology and structure analysis}

The morphology of the as-synthesized mesoporous $\mathrm{TiO}_{2}$ nanoparticles sample was investigated by SEM. Fig. 4a depicted that asobtained mesoporous $\mathrm{TiO}_{2}$ nanoparticles were adhered to by many small size mesoporous particles that are densely distributed inside and outside of the substrate surface. Fig. $4 \mathrm{~b}$ showed that the fine nanoparticles are assembled on the mesoporous surface of $\mathrm{TiO}_{2}$ pores were agglomerated to form large particles (lumps) and the shape of nanoparticles is irregular with their average sizes range around $20-200 \mathrm{~nm}$.

The microstructure of mesoporous $\mathrm{TiO}_{2}$ nanoparticles was further investigated by the TEM technique. Fig. $4 c$ revealed that the higher degree of mesoporous structure and also large number of pores appeared on the surface of the as-prepared mesoporous $\mathrm{TiO}_{2}$ nanoparticles. Fig. 4d showed the HRTEM images of mesoporous $\mathrm{TiO}_{2}$ nanoparticles from there we could be observed that the shape of particles is irregular and their average size ranges 20-70 $\mathrm{nm}$. TEM results are correlated with SEM results.

\subsection{Gas Sensing Properties}

The porous structure plays a vital role in determining the sensing properties by affecting the diffusion of test gases toward sensing material surface [19]. The operating temperature of the sensor is significantly influenced by MOSs based sensors. Therefore, the gas sensing performance of the mesoporous $\mathrm{TiO}_{2}$ nanoparticles to $100 \mathrm{ppm}$ ethanol gas was examined. Fig. 5a revealed the response of the sensor toward $100 \mathrm{ppm}$ ethanol at an operating temperature from $100^{\circ} \mathrm{C}$ to $220^{\circ} \mathrm{C}$. it is found that the response increased with the initial operating temperature, and reached the maximum value at about $180{ }^{\circ} \mathrm{C}$, afterward the response decreased with further increment in temperature then the existence of an optimal temperature was observed, which is finally taken as $180^{\circ} \mathrm{C}$ with the strongest response value of the sensor based on $\mathrm{TiO}_{2}$ is 5.2 at 180 ${ }^{\circ} \mathrm{C}$. The selectivity is a crucial parameter for the gas sensor to evaluate the sensing performances of gas sensors for their practical application. Thus, the selectivity test of the sensor was investigated by exposing several kinds of common gases including ethanol, isopropyl alcohol, and methanol tested with a concentration of $100 \mathrm{ppm}$ at the same temperature of $180{ }^{\circ} \mathrm{C}$ and the results are shown in a bar graph as shown in Fig. 5 b. Clearly, it can be observed that the sensorbased mesoporous $\mathrm{TiO}_{2}$ nanoparticles exhibited a much higher response to ethanol in comparison to any other gases at the same concentration. The response and recovery time also plays a significant role in the 
practical detection of detrimental gases. Fig. 6 showed a dynamic curve of mesoporous $\mathrm{TiO}_{2}$ nanoparticles response and recovery towards $100 \mathrm{ppm}$ ethanol gas at $180^{\circ} \mathrm{C}$ was plotted. The result affirms that the resistance of the sensor instantly changes when the sensor was exposed to targeted gases, and later reached a steady state. The response and recovery time of the sensor to ethanol was within $25 \mathrm{~s}$ and the recovery time was $15 \mathrm{~s}$, respectively.
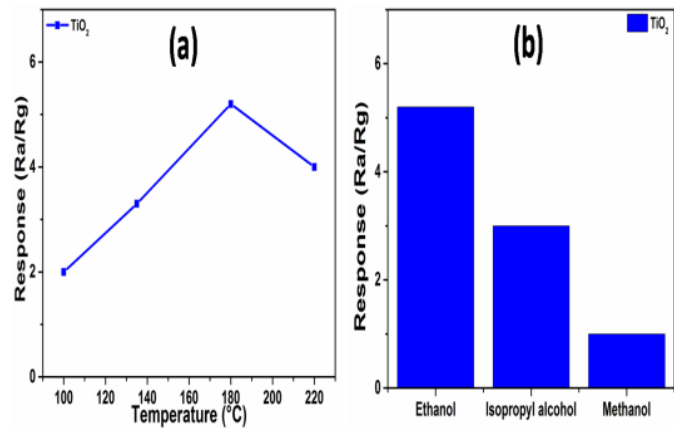

Fig 5. (a) Response of the different mesoporous $\mathrm{TiO} 2$ nanoparticles versus operating temperature to $100 \mathrm{ppm}$ acetone (b) Selectivity of mesoporous $\mathrm{TiO}_{2}$ nanoparticles towards $100 \mathrm{ppm}$ of various gases.

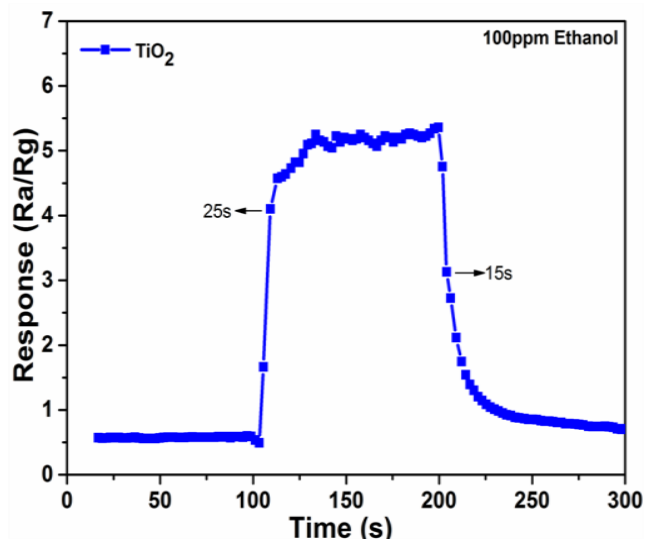

Fig 6. The response-recovery dynamic curve of mesoporous $\mathrm{TiO}_{2}$ nanoparticles to 100 ppm ethanol at $180^{\circ} \mathrm{C}$.

\section{Conclusion}

We have successfully prepared mesoporous $\mathrm{TiO}_{2}$ nanoparticles by a simple and low cost solvo thermal method under the calcinations temperature at $300^{\circ} \mathrm{C}$. The asobtained sample was characterized by various analytic techniques and their gas sensing properties were examined. It is found that the mesoporous structure of $\mathrm{TiO}_{2}$ nanoparticles exhibits high surface area and large pore volume and showed a better performance of ethanol sensing towards $100 \mathrm{ppm}$ at $180^{\circ} \mathrm{C}$ with fast response and recovery times. The enhancements of gas sensing properties were ascribed to the distinctive porous structure.

\section{ACKNOWLEDGMENT}

The author thanks the financial support of the National Natural Science Foundation of China (NSFC 51402065 and 51603053), Natural Science Foundation of Heilongjiang Province (B2015021), Fundamental Research Funds of the Central University, the Application Technology Research and Development Projects of Harbin (2015RAQXJ038) and Defense Industrial Technology Development Program (JCKY2016604C006).

\section{References}

[1]. N. T.A.Thu, N.D. Cuong, L.C. Nguyen, D.Q. Khieu, P.C. Nam, N.V. Toan, C.M. Hung, N.V. Hieu, Fe2O3 nanoporous network fabricated from $\mathrm{Fe} 3 \mathrm{O} 4 /$ reduced graphene oxide for high-performance ethanol gas sensor, Sensors and Actuators B: Chemical, Vol. 255, 2018, pp. 3275-3283.

[2]. D.R. Miller, S.A. Akbar, P.A. Morris, Nanoscale metal oxide-based heterojunctions for gas sensing: A review, Sensors, and Actuators B: Chemical, Vol, 204, 2014, pp. 250-272.

[3]. T. Yuan, Z. Li, W. Zhang, Z. Xue, X. Wang, Z. Ma, Y. Fan, J. Xu, Y. Wu, Highly sensitive ethanol gas sensor based on ultrathin nanosheets assembled 
Bi2WO6 with composite phase, Science Bulletin, Vol. 64, 2019, pp. 595-602.

[4]. M. Tonezzer, L.T.T. Dang, H.Q. Tran, S. Iannotta, Multiselective visual gas sensor using nickel oxide nanowires as chemiresistor, Sensors, and Actuators B: Chemical, Vol. 255, 2018.

[5]. A. Dey, Semiconductor metal oxide gas sensors: A review, Materials Science and Engineering: B, Vol. 229, 2018, pp. 206217.

[6]. N.D. Hoa, S.A. El-Safty, Highly sensitive and selective volatile organic compound gas sensors based on mesoporous nanocomposite monoliths, Analytical Methods, Vol. 3, 2011, pp. 1948-1956.

[7]. R. Wilson, C. Simion, C. Blackman, C. Carmalt, A. Stanoiu, F. Di Maggio, J. Covington, The Effect of Film Thickness on the Gas Sensing Properties of UltraThin TiO2 Films Deposited by Atomic Layer Deposition, Sensors, Vol. 18, 2018, pp. 735.

[8]. M.V. Reddy, G.V. Subba Rao, B.V.R. Chowdari, Metal Oxides and Oxysalts as Anode Materials for Li Ion Batteries, Chemical Reviews, Vol. 113, 2013.

[9]. A. Bertuna, E. Comini, N. Poli, D. Zappa, G. Sberveglieri, Titanium Dioxide Nanostructures Chemical Sensor, Procedia Engineering, Vol. 168, 2016, pp. 313-316.

[10]. C. Wang, Y. Li, P. Qiu, L. Duan, W. Bi, Y. Chen, D. Guo, Y. Liu, W. Luo, Y. Deng, Controllable synthesis of highly crystallized mesoporous $\mathrm{TiO} 2 / \mathrm{WO} 3$ heterojunctions for acetone gas sensing, Chinese Chemical Letters, (2019).

[11]. S. Nasirian, H. Milani Moghaddam, Hydrogen gas sensing based on polyaniline/anatase titania nanocomposite, International Journal of Hydrogen Energy, Vol. 39, 2014, pp. 630-642.

[12]. A. H. Shar, M. N. Lakhan, J. Wang, M.
Q. Dayo, facile synthesis and characterization of selenium nanoparticles by the hydrothermal approach, Digest Journal of Nanomaterials and Biostructures, Vol. 14, 2019, pp. 867-872.

[13]. J. Zhang, X. Liu, G. Neri, N. Pinna, Nanostructured Materials for RoomTemperature Gas Sensors, Advanced Materials, Vol. 28, 2016, pp. 795-831.

[14]. S. Zhang, P. Song, Z. Yang, Q. Wang, Facile hydrothermal synthesis of mesoporous In $2 \mathrm{O} 3$ nanoparticles with superior formaldehyde-sensing properties, Physica E: Low-dimensional Systems and Nanostructures, Vol. 97, 2018, pp. 38-44.

[15]. S. Liu, Z. Wang, H. Zhao, T. Fei, T. Zhang, Ordered mesoporous $\mathrm{Co} 3 \mathrm{O} 4$ for high-performance toluene sensing, Sensors and Actuators B: Chemical, Vol. 197, 2014, pp. 342-349.

[16]. B. Durairaj, T. Xavier, S. Muthu, fungal generated titanium dioxide nanopartilces for uv protective and bacterial resistant fabrication, International Journal of Engineering Science and Technology (IJEST), Vol. 6, 2014, pp. 621-625.

[17]. G. Rajakumar, A. A. Rahuman, S. M. Roopan, V. G. Khanna, G. Elango, C. Kamaraj, A. A. Zahir, K. Velayutham, Fungus-mediated biosynthesis and characterization of $\mathrm{TiO}(2)$ nanoparticles and their activity against pathogenic bacteria, Spectrochim Acta A Mol Biomol Spectrosc, Vol. 91, 2012,

[18]. F. T. L. Muniz, M. A. R. Miranda, C. M. D. Santos, J. M. Sasaki, The Scherrer equation and the dynamical theory of $\mathrm{X}$ ray diffraction, Vol. 72, 2016, pp. 1-6.

[19]. Z. Wen, L. Zhu, Y. Li, Z. Zhang, Z. Ye, Mesoporous $\mathrm{Co} 3 \mathrm{O} 4$ nanoneedle arrays for high-performance gas sensor, Sensors and Actuators B: Chemical, Vol. 203, 2014, pp. 873-879. Ahmed, K. T. Alali, R. Ahmed, I. Ali, A. 